\title{
Research on exploration and exploitation of expatriate: Antecedent and follow-up effect
}

\author{
Liang-Hung Lin ${ }^{1 *}$, Pei-Hsuan Lee ${ }^{2}$, Ching-Yi Wu ${ }^{3}$, Yo-Ling Ho ${ }^{4}$ \\ 1, 2, 3 Department of International Business, National Kaohsiung University of Science and Technology, Kaohsiung, \\ Taiwan \\ ${ }^{4}$ General Education Center, National Taitung Junior College, Taitung, Taiwan
}

\author{
Keywords \\ Self-exploration \\ Personality traits \\ Organizational structure \\ Expatriates' adjustment \\ Foreign assignment
}

Received: 19 October 2017

Accepted: 23 January 2018

Published: 13 February 2018

\begin{abstract}
Employees are important assets of an organization in the current knowledge economy. Thus, the issue of their behavior should be more emphasized and discussed. This study researches how self-exploration/self-exploitation comes into being and their follow-up effect based on the exploration/exploitation in an organization. The former discusses the effect of self-exploration/self-exploitation due to personality traits and organizational structure, the results of which were then used to discuss whether the organizational structure would affect expatriates' adjustment to a foreign assignment. We used multiple regression analysis to test the relationship between selfexploration/self-exploitation, personality traits, organizational structure, and expatriates' adjustment to a foreign assignment. Additionally, the mediation effect of self-exploration on the relationship between personality traits and expatriates' adjustment to the foreign assignment was studied. Our study considers that companies must strengthen self-exploration/exploitation to promote and perform before seeking organizational exploration/exploitation entirely. However, there is no analysis of self-exploration/exploitation.
\end{abstract}

(c) 2018 The Author(s). Published by TAF Publishing.

\section{INTRODUCTION}

Exploration/exploitation has recently been an important issue in organizational management. Various contradictions and dilemma can be seen everywhere in this fluctuating environment. The success of an organization lies in its ability to deal with and even benefit from those contradictions. To achieve this purpose, an organization inevitably faces tradeoff between exploration and exploitation-pursuing the opportunity of exploring future market by radical innovations or incrementally improving and advancing in the current product market. It is therefore important to have an indepth understanding of how to efficiently use exploration and exploitation.

Empirically, it becomes more and more important for an organization to understand how to use exploration and exploitation to achieve the expected goal, thereby improving the overall organizational performance. While the prior studies primarily focused on exploration and exploitation at the organizational level, those at the individual level are limited (Raisch \& Birkinshaw, 2008; Tsai \& Tsai, 2017). Following the development of different studies and theories, exploration and exploitation are no longer constrained in product development or organizational improvement. The concepts of exploration and exploitation can also be applied to a change in individual behavior (including the accumulation and renewal of knowledge) and to a situation when individuals use existing knowledge and technique to continuously improve themselves, respectively. Gupta, Smith, and Shalley (2006) also argue that individual exploration/exploitation is an important determinant of organizational ambidexterity that allows organizations to remain competitive in the long run.

In the era of knowledge economy, employees are not only instruments of production but also important hu-

*corresponding author: Liang-Hung Lin

†email: lhlin@cc.kuas.edu.tw 
man assets for organizations. They are founder of all creations and can turn their creativity into innovative behavior, which makes organizations keep their competitiveness (Damanpour, 1996; Krisnawati, Perangin-Angin, Zainal, \& Suardi, 2016; Lannu \& Nobleza, 2017). Mom, Van Den Bosch, and Volberda (2009) define individual exploration/exploitation as individual learning behavior model and many scholars also indicate that personality may affect individual learning behavior. Additionally, individual exploration/exploitation can be affected by organizations. For instance, under a strict and rigid system, employees may not explicitly show behaviors of exploration/exploitation as their personal style is highly constrained. Hence, organizational structure is also an indispensable factor when we discuss individual exploration/exploitation.

Multinational Companies (MNCs) come into being due to the rise of internationalization, which makes expatriates become important. Behaviors of expatriates not only show whether expatriates succeed or fail in their assignments, but can further affect the MNC's international development. Thus, MNCs must put great emphasis on the selection of expatriates. The main challenge confronting expatriates is an environment of cultural diversity. If an individual has already been open to cross-cultural adjustment, he/she will be easier to stimulate for his/her enthusiasm to explore new things and can be faster to adjust to the new work environment. Therefore, he/she is highly adaptable to the oversea environment, which contributes to the success of global assignment and job performance of expatriates (Abe \& Wiseman, 1983; Chong \& Lee, 2017). How to have the right person in the right place in a global assignment has become an important issue for multinational companies when selecting expatriates. Most part of the studies on this issue were based on the perspective of adjustment and didn't consider individual exploration causing an effect on oversea adjustment. Thus, this study tries to understand the relationship between individual exploration and oversea adjustment and characteristics that expatriates should be possessing of, which contributes to multinational companies when selecting expatriates.

To sum up, exploration/exploitation are emerging issues for organizations and are highly valued. Many researches are also committed to it and empirically study the impact of organizational exploration/exploitation on organizational performance (O'Reilly \& Tushman, 2004). However, previous researches are committed to organizational exploration/exploitation. Hence, the amount of empirical research based on individual exploration/exploitation is still limited. In this study, we investigate the reason of indi- vidual exploration/exploitation form and the follow-up effect based on previous findings on organizational exploration/exploitation. Besides, we analyze the mediation effect of individual exploration.

\section{LITERATURE REVIEW}

\section{Exploration/Exploitation}

\section{Organizational exploration/exploitation}

Prior studies (Gupta et al., 2006; March, 1991) use exploration and exploitation to measure and analyze organizational ambidexterity. Exploration is a process of exploring, absorbing new knowledge and seeking new opportunities that allow organizations to pursue future effectiveness of resource utilization. Exploration is a process of exploring, absorbing new knowledge and seeking for new opportunity. Organizations engaging in exploration can benefit from radical innovation. Exploitation, on the contrary, is a capability of enhancing and extending the existing knowledge. Organizations engaging in exploitation can benefit from incremental innovation (Gupta et al., 2006; March, 1991; Saputri \& Mulyaningsih, 2016). Although it is generally argued that organizations should simultaneously pursue exploration and exploitation for long-term survival, the extent to which exploratory and exploitative activities are required and the resulting use of resources are industry-specific.

\section{Individual exploration/exploitation}

O'Reilly and Tushman (2004) indicate that organizational ambidexterity is composed of ambidextrous behaviors by individual organizational members. Additionally, Laureiro-Martínez, Brusoni, and Zollo (2010) contend that individuals' exploratory and exploitative behaviors involve different cognitive processes. Exploratory behaviors are concerned with pursuing new knowledge and breaking old rules and methods to create value by constantly innovating. Exploration is however low in reliability, time consuming and subject to high costs with low recovery. Exploitative behaviors, on the contrary, are concerned with using familiar methods and working processes to improve individuals' own skills and knowledge to create value by the existing capability or incremental changes. If individuals pay more attention to exploitative than exploratory behaviors, they will be subject to risks of self-destruction. As a result, the trade-off between individual exploration and exploitation is related not only to personal characteristics and organizations' internal and external environments, but also to the conflicts between long-term and short-term goals. In other words, it is difficult to reach the balance between exploration and exploitation at individual, organizational and 
social levels (Levinthal \& March, 1981). This study adopts the viewpoint of Mom et al. (2009) on individual exploration and exploitation, the former of which is considered as an activity that an individual pursues innovation to develop valuable knowledge for the organizations and the latter of which is considered as an activity that an individual pursues systematic procedure to consolidate the existing knowledge.

\section{Personality Traits}

Personality represents the true self including inner habits, motivation, emotion, attitude and thinking. It also shows an individual's unique reaction different from others in objective reality. Such reaction is a result of interactions among genetic, learning, environment and other factors, and manifests in all aspects of the individual's physical and mental characteristics. All these characteristics are called "personality traits". The Big-Five personality dimensions developed by Costa and McCrae (1985) are widely used and highly valid in practice. This study therefore used the Big-Five personality dimensions-neuroticism, extraversion, openness, agreeableness and conscientiousness-to analyze our proposed hypotheses.

\section{Organizational Structure}

Robbins (1983) indicates that organizational structure is used to describe types of organizations' inner relationships. Organizational structure, from an academic point of view, mainly focuses on the power distribution in organizational decision making, as well as strengths and weaknesses of the control system. According to Williams and van Triest (2009), a centralized organization is characterized by highly concentrated decision-making authority by the higher level of the organization's executives while the lower level employees totally depend on the executives' command. In contrast, a decentralized organization generally delegates the decision-making authority to all its business unit and lower-level employees. Moreover, the executive leadership is grounded on horizontal communications and coordination to promote functional innovation. This study adopts types of organizational structure (i.e., centralization and decentralization) proposed by Williams and van Triest (2009) for analysis.

\section{Overseas Adaptation}

Expatriates are confronted by the organization's performance requirements and the problems of environmental adaptation. Oversea adaptation means the extent of fit, familiarity and psychological comfort shown by an individual in different cultural environments. Considering that expatriates' success or failure is affected by their personal quality, organization and the environment, aspects of oversea adaptation should be multifaceted. For example, Black and Stephens (1989) propose three aspects of expatriate adjustment, namely work adjustment (the degree of adjustment to tasks and performance requirements), general adjustment (the degree of adjustment to the living standard of the host country), and interaction adjustment (the degree of adjustment to the social values of the host country). This study mainly used the dimensions of expatriates' oversea adaptation defined by Black (1988), including expatriates' job competency, level of satisfaction with the living standard, and the degree of adjustment to different cultures.

\section{Research Hypothesis}

The relationships between personality traits and selfexploration/self-exploitation Extraversion and self-exploration

Quick and Nelson (1997) argue that individuals with high extraversion tend to try new skills, more effectively motivate self-development, and can quickly adjust themselves to a new environment. For those jobs/tasks demanding high social interactions, employees who score high in extraversion are important assets to managers. Hogan, Curphy, and Hogan (1994) point out that communication is an essential skill in team interaction and individuals characterized by high extraversion are usually good at communication and social activities. Moreover, they are more willing to express their new ideas and more engaged in interactive communications, which helps to generate self-exploration behaviors.

\section{Openness and self-exploration}

Individuals scoring high in openness are keen observers who are more likely to be committed to the development of new thinking and approaches out of curiosity. George and Zhou (2001) also indicated that people of this personality are open-minded and prefer to self-learn various knowledge and skills to respond to different needs in the future. Therefore, individuals characterized by high openness are more likely to have innovative behavior and to adapt to organizational and environmental changes.

\section{Agreeableness and self-exploration/self-exploitation}

Agreeable people are kind to people, show high spirit of teamwork and are willing to achieve organization goal with other members in the organization in a coordinative and cooperative manner. Judge and Bono (2000) indicate that individuals characterized by high agreeableness pay more 
attention to a cooperative relationship. Such personality trait helps work development and the generation of innovative ideas and knowledge in the process of cooperation. Additionally, individuals having the same personality traits can be committed to a closed and harmonious relationship (Organ \& Lingl, 1995). They may therefore prefer to follow the established conventions and avoid verbal conflicts. This study therefore argues that agreeableness can lead to both self-exploration and self-exploitation.

\section{Neuroticism and self-exploitation}

Costa and McCrae (1985) contend that individuals characterized by high neuroticism tend to retain a high state of alertness and passionately pursue perfection in their lives. Additionally, they have high levels of self-perception and pay attention to the feedback given by others. Therefore, they are more likely to follow the systematic procedures, maintain their steady executive competence, and try to make things perfect in avoidance of failures and blames (Quick \& Nelson, 1997).

\section{Conscientiousness and self-exploitation}

Quick and Nelson (1997) argue that individuals characterized by high conscientiousness tend to work hard and accurately. Moreover, they can complete assignments assigned by their supervisors with accuracy and efficiency. Individuals with such personality trait, nonetheless, focus too much on the existing organizational procedures, which inevitably lowers their adaptability to changes (Robbins, 1983). Based on the aforementioned logic, this study hypothesizes that:

H1: Personality traits have a significant impact on selfexploration/self-exploitation.

H1-1: Extraversion has a significant positive impact on self-exploration.

H1-2: Openness has a significant positive impact on selfexploration.

H1-3: Agreeableness has a significant positive impact on self-exploration.

H1-4: Agreeableness has a significant positive impact on self-exploitation.

H1-5: Neuroticism has a significant positive impact on selfexploitation.

H1-6: Conscientiousness has a significant positive impact on self-exploitation.

\section{Openness and oversea adjustment}

Teagarden and Gordon (1995) indicate that individuals with high openness tend to be more flexible and better at making objective judgements. Additionally, they can accept different cultural environments and therefore have less problem of adjustment. George and Zhou (2001) contend that individuals with high openness tend to show curiosity about everything and are able to interact with locals at ease, which helps them quickly adapt to the organization and thereby enhance their work performance.

\section{Agreeableness and oversea adjustment}

The biggest problem that expatriates have is conflicts in interpersonal relationships. Agreeable expatriates tend to build friendship by helping others and working together, through which they can receive trust and assistance from their colleagues (Arthur \& Bennett, 1995). Huang, Chi, and Lawler (2005) also point out that individuals with such personality trait can understand others' feelings and needs, which in turn allows them to build new friendships and great connections in the host country. It is therefore easier for agreeable employees to adjust to the tasks and life styles in the host country.

\section{Conscientiousness and oversea adjustment}

Ones and Viswesvaran (1999) consider conscientiousness as a decisive factor in the degree of oversea adaptation, oversea assignment completion and oversea job performance. Individuals characterized by high conscientiousness can solve problems and take the initiative in dealing with contingencies. Costa and McCrae (1985) also indicate that highly conscientious individuals tend to have a strong sense of responsibility and work efficiency. Instead of avoiding challenge, they will try very hard to solve all the problems confronting them. This personality trait will therefore enhance expatriates' oversea adjustment.

\section{Neuroticism and oversea adjustment}

Ward, Leong, and Low (2004) argue that expatriates characterized by high neuroticism tend to be sensitive and have high standards towards themselves, which can cause excessive stress about future contingencies. Tellegen (1985) thinks that neuroticism arises from environmental uncertainties and individuals with such personality trait pay too much attention to details. Higher pressure is therefore more likely to occur and in turn has a negative effect on physical and mental health, job satisfaction, and oversea adjustment (Ward et al., 2004). Based on the aforementioned logic, this study hypothesizes that:

H2: Personality traits have a significant impact on oversea adjustment. 
H2-1: Extraversion has a significant positive impact on oversea adjustment.

H2-2: Openness has a significant positive impact on oversea adjustment.

H2-3: Agreeableness has a significant positive impact on oversea adjustment.

H2-4: Conscientiousness has a significant positive impact on oversea adjustment.

H2-5: Neuroticism has a significant negative impact on oversea adjustment.

The relationships between organizational structure and self-exploration/self-exploitation

Organizational structure measured in this study is based on the prior literature on the allocation of authority. By focusing on decentralization, this study argues that the environment of decentralized organization engages employees in open communication and encourages them to develop innovative ideas, as well as flexible, rapid-response capability, all of which can further lead to employees' innovative behaviors.

\section{Decentralized organization and self-exploration}

The higher the degree of decentralization in an organization, the higher the degree of employees' participation in decision making. Therefore, internal organization can offer open communication channels that allow employees to have more flexibility and adaptability, and thereby to innovate progressively (Hewett \& Bearden, 2001). Chang and Lee (2007) indicate that decentralized organization adapting unofficial control system will help internal managers and employees challenge and take risks (e.g., engaging in innovative activities with regards to products, techniques and progress). Self-exploitation follows formal rule, institution and standard operating procedures to make him/her accurately and fast finish assignments assigned by the organization. Its characteristic is different from a decentralized organization. So this study hypothesizes decentralized organization has a significant negative impact on selfexploitation.

\section{Decentralized organization and self-exploitation}

Strategy of self-exploitation tends to be conservative and devoted to maintaining existing market. It focuses on improving working efficiency to lower the cost and keep stable on organizational execution, which is suitable for centralized organizations. Lin and Germain (2003) indicated that centralized organization is based on strict relationship between upper and lower classes, clear division of labor and standardization to make employees reduce mistakes and improve efficiency. Centralized organization reduces employees' control of work and weaken one's possibility of pursuing revolution and new solution, which is harmful to execute explorative tasks (Atuahene-Gima, 2003).

According to the above related reviews, this study tried to test the relationship between organizational structure and self-exploration/exploitation. We make hypothesis 3 as follows:

H3: Organizational structure has a significant impact on self-exploration/exploitation.

H3-1: Organizational structure of decentralization has a significant positive impact on self-exploration.

H3-2: Organizational structure of decentralization has a significant negative impact on self-exploitation.

\section{The relationship between self-exploration and oversea adjustment}

Caligiuri (2000) suggest that the factors affecting foreign assignments include: (1) the aspect of interpersonal relationship: tolerability of uncertainty, behavioral flexibility and lower ethnocentrism; and (2) motivational state: aspiration of acquiring new behavior and the interest in the culture of the countries where expatriates are assigned. Moreover, Hung-Wen (2007) analyzes Taiwanese expatriates stationed in USA and finds that if one cannot fit in new cultural environments and does not have enough learning interest, he/she may fail in foreign assignments. Black and Mendenhall (1990) have also suggested that individuals characterized by self-exploration are more willing to try different new skills, thereby accelerating their passion of exploration and better adjusting to foreign assignments. Individuals characterized by self-exploitation, on the contrary, tend to prefer steady execution and standard processes, which decreases their flexibility (Organ \& Lingl, 1995).

Expatriates face many difficulties during foreign dispatch. Self-exploration however will help expatriates overcome and adjust to the local environment. Explorers tend to be excited about new development opportunities and new things, which makes them quickly adjust to their new working environment and have a higher level of task completion. Huang et al. (2005) suggest that explorers are more autonomous and therefore easier to devote themselves to foreign assignments. Black and Mendenhall (1990) have also contended that employees for long-term dispatch need to interact with local people and establish their own social network. Under the circumstances, explorers, since they are good at communicating and socializing as well as have better problem-solving skills, have a greater capacity to adjust 
to the local environment and solve problems during foreign dispatch (Caligiuri, 2000). In contrast, self-exploitation will not have a direct effect on oversea adjustment. Based on the above arguments, we hypothesize that:

H4: Self-exploration has a significant positive impact on overseas adjustment.

\section{The mediation effect of self-exploration}

personality traits will show different levels of adjustment, which consequently affects their job performance. In other words, expatriates who have the propensity to pursue innovation and change are more likely to embrace uncertainties and show explorative behaviors, thereby helping them adjust to the exotic foreign culture (Leonard-Barton, 1992).

Self-exploration can determine whether expatriates' behaviors and job performance meet the requirements by the MNCs and whether they can adjust to the foreign environment. The pursuit of innovation and developing new ideas in self-exploration can facilitate expatriates' adjustment to a dynamic environment (Quick \& Nelson, 1997). Moreover, in the process of adjusting to the environment, expatriates will become aware of their stress resistance and learning abilities. The resulting sense of achievement will then facilitate their oversea adjustment (Black \& Mendenhall, 1990). Based on the aforementioned arguments, this study argues that self-exploration can mediate the relationship between personality traits and overseas adjustment. Therefore:

H5: Self-exploration has a mediation effect on personality trait and overseas adaption.

\section{RESEARCH METHOD}

\section{Data Collection}

Questionnaires were sent to EMBA alumni of Kaohsiung University of Applied Sciences who then further distributed the questionnaires to expatriates working in the financial, telecommunication, electronics manufacturing, and manufacturing industries. We also sent additional emails requesting the respondents for further explanation. This study collected 228 questionnaires, among which 215 were valid. The effective response rate was $94.3 \%$.

\section{Measurement Method}

\section{Self-exploration/exploitation}

This study adopts Mom et al. (2009) division of manager's exploration/exploitation-self-exploration and selfexploitation. The questionnaire contains 13 question items, with the fifth question item being deleted after the factor analysis. The operational definitions of self-exploration and self-exploitation are as follows:

- Self-exploration:
Individuals who focus on new knowledge, challenge risky activities, break through out of date working practices and create value from innovation.

- Self-exploitation:

Individual preferring using familiar working skills and procedures, progressively improving self-skills and knowledge, following established working practices and creating value from existing or slightly variable capability.

\section{Personality traits}

Costa and McCrae (1985) divided the personality traits into five aspects including Neuroticism, Extraversion, Openness, Agreeableness and Conscientiousness, and we use it as a reference. Initial questionnaire included 22 items, and the items No.17 and 18 were pruned off after factor analysis. Finally, we used the remaining 20 items as our questionnaire items.

- Neuroticism:

The man who maintains a high level of alertness, does everything cautiously and wants himself/herself and others to be perfect.

- Extraversion:

The man who pursues excitement, loves to be social and is good at communicating.

- Openness:

One's level of exploring, absorbing unfamiliar things and proactively seeking new experience.

- Agreeableness:

The man who has friendly behavior and thinking is easier to establish close relationships.

- Conscientiousness:

The man who is responsible, thoughtful and perseverant.

\section{Organizational structure}

Williams and van Triest (2009) divided the decentralization into four items : the organization that has parallel communication and coordinate focuses on employees' capability and motivation and encourages them to develop new skill, which makes them have a quick adaptation to the new environment, and we use it as a reference.

\section{Overseas adaption}

Black (1988) divided the overseas adaption into eleven items: expatriates' level of competence, level of life satisfaction and level of cross-cultural adaptation, and we use it as a reference.

\section{Control variables}

There were many demographics of expatriates in overseas 
literatures like gender, age, education level and dispatched seniority, and researches showed that those demographics do affect the overseas adaption. Thus, our study measured expatriates' gender, age, education level, dispatched seniority, total seniority and position as our control variables.

\section{EMPIRICAL ANALYSIS \\ Multiple Regression Analysis \\ Multiple regression analysis of personal trait on self- exploration/exploitation}

To test $\mathrm{H} 1$ by multiple regression analysis, which assumed that different personality trait has a significant impact on self-exploration/exploitation, we use five aspects of per- sonal trait as independent variable and two aspects of selfexploration/exploitation as dependent variable. The following are our analysis results.

The impact of personal trait on self-exploration. According to Table $1, R^{2}=0.263$ and $F=6.590$, which achieves significant level $(p<0.001)$. Five aspects of personal trait can explain $26.3 \%$ sum of squares of self-exploration, appearing significant explanatory ability. Among five aspects of personal trait, Extraversion $(\beta=0.169, p<0.1)$ and Openness ( $\beta=0.355, p<0.01$ ) have significant positive effect on selfexploration, and Agreeableness ( $\beta=0.053$ ) has no significant effect on self-exploration. Thus, both of H1-1nd H1-2 are supported but H1-3 isn't supported.

TABLE 1. Multiple regression analysis of personal trait on self-exploration/exploitation $(n=215)$

\begin{tabular}{lcccc}
\hline \hline & \multicolumn{3}{c}{ Self-exploration/exploitation } \\
\hline Dependent Variable & \multicolumn{3}{c}{ Self-Exploration } & \multicolumn{2}{c}{ Self-Exploration } \\
\cline { 2 - 5 } & Mode 1 & Mode 2 & Mode 1 & Mode 2 \\
\hline \hline Control variable & & & & \\
Gender & -0.059 & -0.017 & $0.112^{\dagger}$ & 0.061 \\
Age & -0.102 & -0.079 & -0.001 & -0.046 \\
Education level & 0.058 & -0.049 & $-0.267^{* *}$ & $-0.254^{* *}$ \\
Total seniority & -0.055 & -0.055 & -0.009 & 0.027 \\
Position & $0.167^{\dagger}$ & $0.172^{*}$ & -0.020 & -0.033 \\
Dispatched seniority & $0.171^{*}$ & 0.119 & -0.044 & -0.011 \\
Independent variable & & & & \\
Neuroticism & & -0.001 & & $0.214^{* *}$ \\
Extraversion & & $0.169^{\dagger}$ & & -0.074 \\
Openness & & $0.355^{* *}$ & & -0.128 \\
Agreeableness & & 0.053 & & $0.209^{* *}$ \\
Conscientiousness & & 0.045 & $3.427^{* *}$ & $0.186^{*}$ \\
$F$ & $2.612^{*}$ & $6.590^{* * *}$ & 0.090 & 0.188 \\
$R^{2}$ & 0.070 & 0.263 & & \\
\hline \hline
\end{tabular}

Note: ${ }^{\dagger} p<0.1,{ }^{*} p<0.05,{ }^{* *} p<0.01,{ }^{* * *} p<0.001$

The impact of personal trait on self-exploitation. According to Table $1, R^{2}=0.188$ and $F=4.286$, which achieves significant level $(p<0.001)$. Five aspects of personal trait can explain $18.8 \%$ sum of squares of self-exploitation, appearing significant explanatory ability. Among five aspects of personal trait, Neuroticism $(\beta=0.214, p<0.01)$, Agreeableness $(\beta=0.209, p<0.01)$ and Conscientiousness $(\beta=0.186$, $p<0.05$ ) have significant positive effect on self-exploitation. Thus, H1-4, H1-5 and H1-6 are supported.

\section{Multiple regression analysis of personal trait on over- seas adaptation}

To test $\mathrm{H} 2$ by multiple regression analysis, which assumed that different personality trait has a significant impact on overseas adaptation, we used five aspects of personal trait as independent variable and an aspect of overseas adaptation as dependent variable. The following are our analysis results.

According to Table $2, R^{2}=0.209$ and $F=4.878$, which achieves significant level $(p<0.001)$. Five aspects of personal trait can explain $20.9 \%$ sum of squares of overseas adaption, appearing significant explanatory ability. Among five aspects of personal trait, Extraversion $(\beta=0.237, p<$ $0.01)$, Openness $(\beta=0.134, p<0.1)$ and Agreeableness $(\beta$ $=0.166, p<0.05$ ) have a significant positive effect on overseas adaptation, and Conscientiousness $(\beta=0.058)$ has no significant positive effect on overseas adaptation. Besides, 
TABLE 2. Multiple regression analysis of personal

\begin{tabular}{lcc}
\multicolumn{3}{c}{ trait on overseas adaptation $(n=215)$} \\
\hline \hline Dependent Variable & \multicolumn{2}{c}{ Overseas } \\
\cline { 2 - 3 } & Mdaption \\
\hline \hline Control variable & Mode 2 \\
Gender & 0.024 & 0.049 \\
Age & 0.012 & 0.014 \\
Education level & $0.185^{*}$ & 0.111 \\
Total seniority & -0.048 & -0.044 \\
Position & 0.047 & 0.056 \\
Dispatched seniority & $0.145^{\dagger}$ & $0.140^{\dagger}$ \\
Independent variable & & \\
Neuroticism & & -0.006 \\
Extraversion & & $0.237^{* *}$ \\
Openness & & $0.134^{\dagger}$ \\
Agreeableness & & $0.166^{*}$ \\
Conscientiousness & & -0.058 \\
$F$ & $2.228^{*}$ & $4.878^{* * *}$ \\
$R^{2}$ & 0.060 & 0.209 \\
\hline \hline
\end{tabular}

Note: ${ }^{\dagger} p<0.1,{ }^{*} p<0.05,{ }^{* *} p<0.01,{ }^{* * *} p<0.001$

Neuroticism $(\beta=-0.006)$ has no significant negative effect on s overseas adaption. Thus, $\mathrm{H} 2-1, \mathrm{H} 2-2$ and $\mathrm{H} 2-3$ are supported but H2-4 and H2-4 aren't supported.

\section{Multiple regression analysis of organizational structure on self-exploration/exploitation}

To test $\mathrm{H} 3$ by multiple regression analysis, which assumed that organizational structure has a significant impact on self-exploration/exploitation, we used organizational structure of decentralization as independent variable and two aspects of self-exploration/exploitation as dependent variable. The following are our analysis results. The impact of organizational structure on self-exploration. According to Table $3, R^{2}=0.246$ and $F=9.646$, which achieves significant level $(p<0.001)$. Organizational structure of decentralization can explain $24.6 \%$ sum of squares of self-exploitation, appearing significant explanatory ability. Organizational structure of decentralization $(\beta=0.426$, $p<0.001$ ) has significant positive effect on self-exploration. Thus, H3-1 is supported.

The impact of organizational structure on self-exploitation. According to Table 3, $R^{2}=0.199$ and $F=7.333$, which achieves significant level $(p<0.001)$. Organizational struc- ture of decentralization can explain $19.9 \%$ sum of squares of self-exploitation, appearing significant explanatory ability. Organizational structure of decentralization $(\beta=$ $-0.335, p<0.001$ ) has significant negative effect on selfexploitation. Thus, H3-2 is supported.

\section{Multiple regression analysis of self-exploration/exploit- ation on overseas adaption}

To test the hypothesis $\mathrm{H} 4$ by multiple regression analysis, which assumed that self-exploration/exploitation on has a significant impact on overseas adaptation, we used two aspects of self-exploration/exploitation as independent variable and overseas adaptation as dependent variable. The following is our analysis results.

According to Table $4, R^{2}=0.174$ and $F=5.439$, which achieves significant level $(p<0.001)$. Two aspects of selfexploration/exploitation can explain $17.4 \%$ sum of squares of overseas adaption, appearing significant explanatory ability. Among two aspects of self-exploration/exploitation, self-exploration $(\beta=0.373, p<0.001)$ has a significant positive effect on overseas adaptation but self-exploration hasn't. Thus, $\mathrm{H} 4$ is supported. 
TABLE 3. Multiple regression analysis of organizational structure on self-exploration/ exploitation $(n=$ 215)

\begin{tabular}{lcccc}
\hline \hline & \multicolumn{3}{c}{ Self-exploration/exploitation } \\
\hline Dependent Variable & \multicolumn{3}{c}{ Self-Exploration } & \multicolumn{2}{c}{ Self-Exploration } \\
\cline { 2 - 5 } & Mode 1 & Mode 2 & Mode 1 & Mode 2 \\
\hline \hline Control variable & & & & \\
Gender & -0.059 & -0.077 & $0.112^{\dagger}$ & $0.125^{\dagger}$ \\
Age & -0.102 & -0.092 & -0.001 & -0.009 \\
Education level & 0.058 & 0.051 & $-0.267^{* *}$ & $-0.262^{* *}$ \\
Total seniority & -0.055 & -0.062 & -0.009 & -0.003 \\
Position & $0.167^{\dagger}$ & 0.084 & -0.020 & 0.045 \\
Dispatched seniority & $0.171^{*}$ & $0.217^{* *}$ & -0.044 & -0.080 \\
Independent variable & & & & \\
Decentralization & & $0.426^{* * *}$ & & $-0.335^{* * *}$ \\
$F$ & $2.612^{*}$ & $9.646^{* * *}$ & $3.427^{* *}$ & $7.333^{* * *}$ \\
$R^{2}$ & 0.070 & 0.246 & 0.090 & 0.199 \\
\hline \hline
\end{tabular}

Note: ${ }^{\dagger} p<0.1,{ }^{*} p<0.05,{ }^{* *} p<0.01,{ }^{* * *} p<0.001$

TABLE 4. Multiple regression analysis of self-exploration/exploitation on overseas adaption $(n=215)$

\begin{tabular}{|c|c|c|}
\hline \multirow[t]{2}{*}{ Dependent Variable } & \multicolumn{2}{|c|}{ Overseas Adaption } \\
\hline & Mode 1 & Mode 2 \\
\hline \multicolumn{3}{|l|}{ Control variable } \\
\hline Gender & 0.024 & 0.036 \\
\hline Age & 0.012 & 0.050 \\
\hline Education level & $0.185^{* *}$ & $0.186^{* *}$ \\
\hline Total seniority & -0.048 & -0.027 \\
\hline Position & 0.047 & -0.014 \\
\hline Dispatched seniority & $0.145^{\dagger}$ & 0.085 \\
\hline \multicolumn{3}{|l|}{ Independent variable } \\
\hline Self-exploration & & $0.373^{* * *}$ \\
\hline Self-exploitation & & 0.084 \\
\hline$F$ & $2.228^{* *}$ & $5.439 * * *$ \\
\hline$R^{2}$ & 0.060 & 0.174 \\
\hline
\end{tabular}

\section{Mediating Effect Analysis}

We tested whether self-exploration has a mediation effect on personality trait and overseas adaptation based on the way proposed by Baron and Kenny (1986). The process has to conform to three conditions: (1) independent variable and mediation variable respectively make significant effect on dependent variable; (2) the relationship between independent variable and mediation variable is significant; and (3) the relationship between independent variable and dependent variable is weakened by mediation variable. It's mediating effect if the relationship between independent variable and dependent variable turn out to be unobvious because of mediation variable. However, if the relationship between independent variable and dependent variable is weakened by mediation variable but still significant, it's partial mediating effect. The following are our analysis results.

\section{Mediating effect of self-exploration on extraversion and overseas adaptation}

The analyzing result of mediation variable as is shown in Table 5. First, there is a significant positive relationship between extraversion and overseas adaptation $(p<0.01)$. 
TABLE 5. Mediating effect of self-exploration on personality trait and overseas adaption $(n=215)$

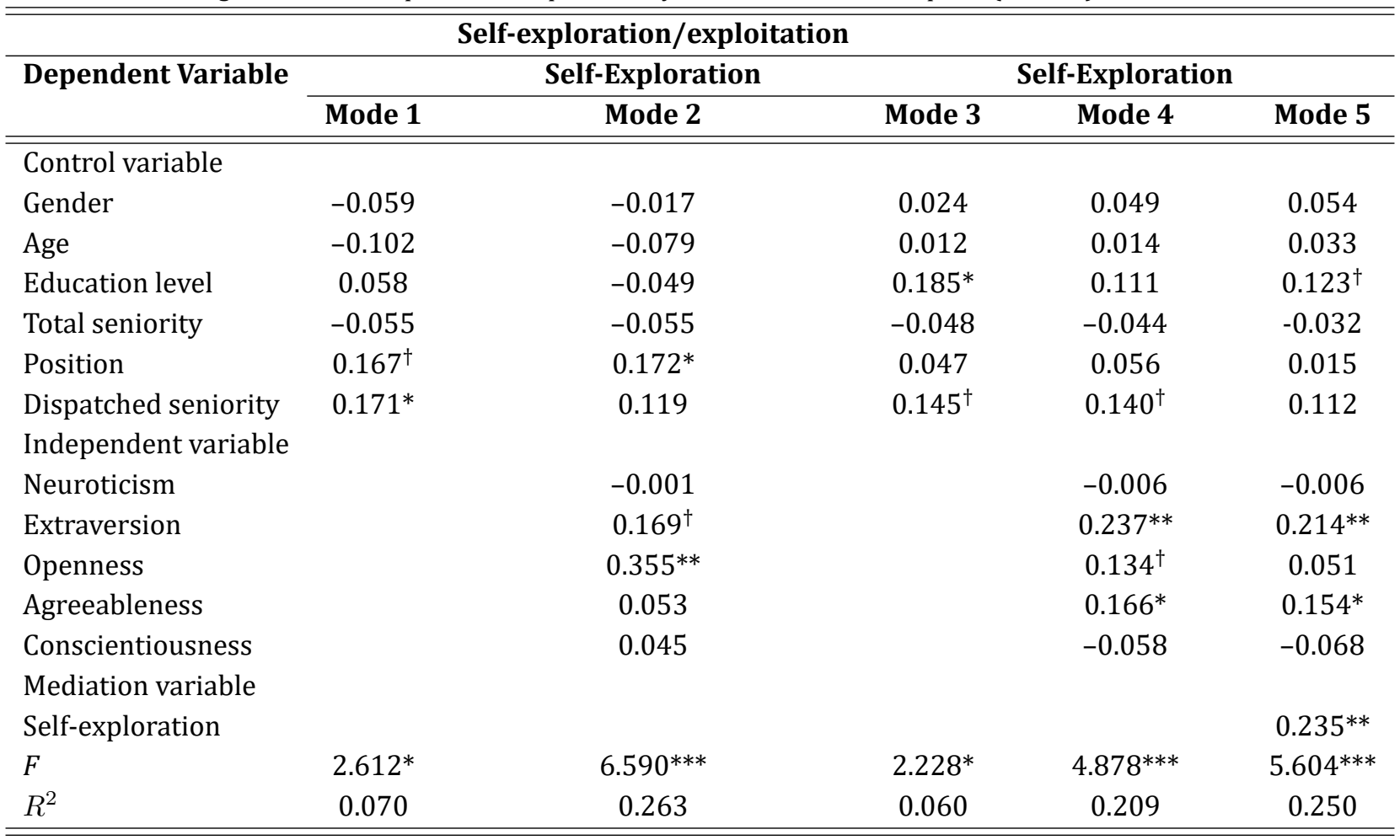

Note: ${ }^{\dagger} p<0.1,{ }^{*} p<0.05,{ }^{* *} p<0.01,{ }^{* * *} p<0.001$

Second, there is a significant positive relationship between extraversion and self-exploration $(p<0.1)$. Finally, according to Table 5, the regression coefficient of extraversion on overseas adaptation reduces from $0.237(p<0.01)$ to $0.214(p<0.01)$ after putting into self-exploration. Thus, self-exploration has partial mediating effect between extraversion and overseas adaptation.

\section{Mediating effect of self-exploration on openness and overseas adaption}

The analysis results of mediation variable are as shown in Table 5. First, there is a significant positive relationship between openness and overseas adaption $(p<0.1)$. Second, there is a significant positive relationship between openness and self-exploration $(p<0.01)$. Finally, according to Table 5, the regression coefficient of openness on overseas adaptation reduces from $0.134(p<0.1)$ to 0.051 after putting into self-exploration. Thus, self-exploration has a mediating effect between openness on overseas adaptation.

\section{Mediating effect of self-exploration between neuroti- cism, agreeableness, conscientiousness and overseas adaption}

The analyzing result of mediation variable as is shown in Table 5. Neuroticism, agreeableness and conscientiousness don't conform to those three conditions proposed by
Baron and Kenny (1986). Thus, self-exploration has no mediating effect on neuroticism, agreeableness and conscientiousness and overseas adaptation. In conclusion, our study approves that extraversion and openness do affect self-exploration and self-exploration also has a mediating effect on extraversion, openness and overseas adaptation. Thus, self-exploration has a partial mediating effect on personality traits and overseas adaptation. H5 is partially supported.

\section{DISCUSSION \& CONCLUSION}

Personality Traits, Organizational Structure and SelfExploration/Exploitation

The study shows that extraversion and openness have significant positive effect on self-exploration. The person with extraversion and openness is progressive and willing to seek for innovation and change to be qualified for new idea and new context, which benefits self-exploration. Agreeableness, neuroticism and conscientiousness have significant positive effect on self- exploitation. The person with agreeableness values personal relationship and intend to obey the manager's instructions. Besides, the person with neuroticism and conscientiousness cautiously view his/her work and responsibly execute it to avoid failure and blame, which benefits self-exploitation. 
The study shows that organizational structure of decentralization has a significant positive impact on selfexploration. Organizational structure of decentralization makes managers and colleagues pay attention to employees by inspiring them bring up new ideas, which benefits self-exploration. However, organizational structure of decentralization has significant negative effect on selfexploitation because self-exploitation follows distinct division of labor to reduce role ambiguity.

\section{Personality Traits, Self-Exploration and Overseas Adap- tion}

The study shows that extraversion, openness and agreeableness have a significant positive effect on overseas adaptation. The person with extraversion, openness and agreeableness is possessed with abilities of sympathy, sociality and communication to make himself/herself easier to establish new relationship and fit in local working environment, and then improve working performance.

The study also shows that self-exploration has a significant positive effect on overseas adaptation. Explorers are active and curious, so they have more passion to explore and adapt different cultural type to fit in local working environment, which also has positive effect on exploring new customers. Moreover, what expatriates need most in overseas company is to establish personal relationship, and explorers are possessed with abilities of sociality and communication, which make them have better ability of solving problems in foreign assignment.

\section{Mediating Effect}

The study shows that self-exploration has partial mediating effect between personality traits and overseas. The effect of personality traits on overseas adaption will be better through self-exploration. Many scholars have pointed out that personality traits will only be effective with circumstances and exploring behavior will be different because it's easy to be affected by character, organization and environment. In other words, there is a great relationship between overseas adaptation and the individual. Expatriates can understand they have enough stress resistance and learning ability through self-exploration, which makes them have a higher sense of accomplishment to adapt to overseas environment. Our study thinks that it will be easier to exert positive effect and inspire employees' creativity and innovation than single context if an organization takes advantage of nearby situational factor and self-exploration. Besides, expatriates will be more willing to finish difficult foreign assignment when facing multinational problems and have a positive effect on overseas adaptation.

\section{Research Implications}

The exploration/exploitation has been the key to keeping an organization balanced and progressive in a competitive and rapidly changing environment recently. Many scholars have also started to research this issue but they mostly focus on organizational exploration/exploitation instead of self-exploration/exploitation. Our study considers that companies have to strengthen self-exploration/exploitation to entirely promote and perform before seeking organizational exploration/exploitation. However, there is no analysis about self-exploration/exploitation. Our research is aimed at this gap and develops the frame of it. We use personality traits and organizational structure as our antecedent factors, and overseas adaptation as our follow-up effect. Finally, we investigate the mediating effect of selfexploration, and the result supports our hypotheses.

Most of the past studies of expatriates focused on strategies, and seldom directly discussed the relationship between factors of personal level and overseas adaptation. Through our study's result, we can preliminarily infer that self-exploration has a significant positive effect on overseas adaptation, which helps for promoting the success of foreign assignment. Thus, if multinationals can take advantage of expatriates' characters to find someone who is suitable for a foreign assignment, it must drive enterprises to expand overseas.

\section{REFERENCES}

Abe, H., \& Wiseman, R. L. (1983). A cross-cultural confirmation of the dimensions of intercultural effectiveness. International Journal of Intercultural Relations, 7(1), 53-67. doi:https://doi.org/10.1016/0147-1767(83)90005-6

Arthur, W., \& Bennett, W. (1995). The international assignee: The relative importance of factors perceived to contribute to success. Personnel Psychology, 48(1), 99-114. doi:https://doi.org/10.1111/j.1744-6570.1995.tb01748.x

Atuahene-Gima, K. (2003). The effects of centrifugal and centripetal forces on product development speed and quality: How does problem solving matter? Academy of Management Journal, 46(3), 359-373. doi:https://doi.org/10.2307/ 30040629 
Baron, R. M., \& Kenny, D. A. (1986). The moderator mediator variable distinction in social psychological research: Conceptual, strategic, and statistical considerations. Journal of Personality and Social Psychology, 51(6), 1173. doi:https://doi.org/ 10.1037//0022-3514.51.6.1173

Black, J. S. (1988). Work role transitions: A study of american expatriate managers in japan. Journal of International Business Studies, 19(2), 277-294. doi:https://doi.org/10.1057/palgrave.jibs.8490383

Black, J. S., \& Mendenhall, M. (1990). Cross-cultural training effectiveness: A review and a theoretical framework for future research. Academy of Management Review, 15(1), 113-136. doi:https://doi.org/10.5465/amr.1990.11591834

Black, J. S., \& Stephens, G. K. (1989). The influence of the spouse on american expatriate adjustment and intent to stay in pacific rim overseas assignments. Journal of Management, 15(4), 529-544. doi:https://doi.org/10.1177/ 014920638901500403

Caligiuri, P. M. (2000). The big five personality characteristics as predictors of expatriate's desire to terminate the assignment and supervisor-rated performance. Personnel Psychology, 53(1), 67-88. doi:https://doi.org/10.1111/j.1744-6570 .2000.tb00194.x

Chang, S.-C., \& Lee, M.-S. (2007). The effects of organizational culture and knowledge management mechanisms on organizational innovation: An empirical study in taiwan. The Business Review, 7(1), 295-301.

Chong, C. Y., \& Lee, T. S. (2017). Employee retention and job performance attributes in private institutions of higher education. International Journal of Business and Administrative Studies, 3(5), 158-165. doi:https://doi.org/10.20469/ ijbas.3.10001-5

Costa, P. T., \& McCrae, R. R. (1985). The neo personality inventory. Odessa, FL: Psychological Assessment Resources.

Damanpour, F. (1996). Organizational complexity and innovation: Developing and testing multiple contingency models. Management Science, 42(5), 693-716. doi:https://doi.org/10.1287/mnsc.42.5.693

George, J. M., \& Zhou, J. (2001). When openness to experience and conscientiousness are related to creative behavior: An interactional approach. Journal of Applied Psychology, 86(3), 513-524. doi:https://doi.org/10.1037//0021-9010.86 .3 .513

Gupta, A. K., Smith, K. G., \& Shalley, C. E. (2006). The interplay between exploration and exploitation. Academy of Management Journal, 49(4), 693-706. doi:https://doi.org/10.5465/amj.2006.22083026

Hewett, K., \& Bearden, W. O. (2001). Dependence, trust, and relational behavior on the part of foreign subsidiary marketing operations: Implications for managing global marketing operations. Journal of Marketing, 65(4), 51-66. doi:https:// doi.org/10.1509/jmkg.65.4.51.18380

Hogan, R., Curphy, G. J., \& Hogan, J. (1994). What we know about leadership: Effectiveness and personality. American Psychologist, 49(6), 493-504. doi:https://doi.org/10.1037//0003-066x.49.6.493

Huang, T.-J., Chi, S.-C., \& Lawler, J. J. (2005). The relationship between expatriates' personality traits and their adjustment to international assignments. The International Journal of Human Resource Management, 16(9), 1656-1670. doi:https:// doi.org/10.1080/09585190500239325

Hung-Wen, L. (2007). Factors that influence expatriate failure: An interview study. International Journal of Management, 24(3), 403-420.

Judge, T. A., \& Bono, J. E. (2000). Five-factor model of personality and transformational leadership. Journal of Applied Psychology, 85(5), 751-765. doi:https://doi.org/10.1037//0021-9010.85.5.751

Krisnawati, N., Perangin-Angin, L. K., Zainal, M., \& Suardi, I. (2016). Brand equity analysis and its impact on the loyal customer of local batik to develop its competitiveness (An empirical study of Batik Banten in South Tangerang). Journal of Administrative and Business Studies, 2(4), 189-207. doi:https://doi.org/10.20474/jabs-2.4.5

Lannu, J. E., \& Nobleza, M. F. L. (2017). The impact of competitiveness on the employability of Philippines industrial designers: Streamlining the program with the international market. International Journal of Business and Administrative Studies, 3(1), 30-36. doi:https://doi.org/10.20469/ijbas.3.10005-1

Laureiro-Martínez, D., Brusoni, S., \& Zollo, M. (2010). The neuroscientific foundations of the exploration-exploitation dilemma. Journal of Neuroscience, Psychology, and Economics, 3(2), 95-115. doi:https://doi.org/10.1037/a0018495

Leonard-Barton, D. (1992). Core capabilities and core rigidities: A paradox in managing new product development. Strategic Management Journal, 13(S1), 111-125. doi:https://doi.org/10.1002/smj.4250131009 
Levinthal, D., \& March, J. G. (1981). A model of adaptive organizational search. Journal of Economic Behavior \& Organization, 2(4), 307-333.

Lin, X., \& Germain, R. (2003). Organizational structure, context, customer orientation, and performance: lessons from Chinese state-owned enterprises. Strategic Management Journal, 24(11), 1131-1151. doi:https://doi.org/10.1002/ smj.348

March, J. G. (1991). Exploration and exploitation in organizational learning. Organization Science, 2(1), 71-87. doi:https:// doi.org/10.1287/orsc.2.1.71

Mom, T. J., Van Den Bosch, F. A., \& Volberda, H. W. (2009). Understanding variation in managers' ambidexterity: Investigating direct and interaction effects of formal structural and personal coordination mechanisms. Organization Science, 20(4), 812-828. doi:https://doi.org/0.1287/orsc.1090.0427

Ones, D. S., \& Viswesvaran, C. (1999). Relative importance of personality dimensions for expatriate selection: A policy capturing study. Human Performance, 12(3-4), 275-294. doi:https://doi.org/10.1207/s15327043hup1203\\&4_4

O'Reilly, C. A., \& Tushman, M. L. (2004). The ambidextrous organization. Harvard Business Review, 82(4), 74-81. doi:https:// doi.org/10.2307/41165852

Organ, D. W., \& Lingl, A. (1995). Personality, satisfaction, and organizational citizenship behavior. The Journal of Social Psychology, 135(3), 339-350. doi:https://doi.org/10.1080/00224545.1995.9713963

Quick, D., \& Nelson, J. (1997). Organizational behavior: Foundations, realities, and challenges. Nashville, TN: SouthWestern Publishing Group.

Raisch, S., \& Birkinshaw, J. (2008). Organizational ambidexterity: Antecedents, outcomes, and moderators. Journal of Management, 34(3), 375-409. doi:https://doi.org/10.1177/0149206308316058

Robbins, S. P. (1983). Organization theory: Structures, designs, and applications, 3/e. Englewood Cliffs, NJ: Prentice-Hall.

Saputri, M. E., \& Mulyaningsih, H. D. (2016). Blue ocean strategy for creating value innovation: A study over kedai digital in Yogyakarta, Indonesia. Journal of Administrative and Business Studies, 1(1), 14-20.

Teagarden, M., \& Gordon, G. (1995). Corporate selection strategies and expatriate manager success. In J. Selmer (Ed.), Expatriate management: New ideas for international business. Westport, CT: Quorum Books.

Tellegen, A. (1985). Structures of mood and personality and their relevance to assessing anxiety with an emphasis on selfreport. In A.H. Tuma \& J.D. Master (Eds.), Anxiety and the anxiety disorders. New Jersy, NJ: Erlbaum.

Tsai, M. S., \& Tsai, M. (2017). The influence of loyalty, participation and obedience on organizational citizenship behavior. International Journal of Business and Economic Affairs, 2(1), 67-76. doi:https://doi.org/10.24088/ijbea-2017-21009

Ward, C., Leong, C.-H., \& Low, M. (2004). Personality and sojourner adjustment: An exploration of the big five and the cultural fit proposition. Journal of Cross-Cultural Psychology, 35(2), 137-151. doi:https://doi.org/10.1177/ 0022022103260719

Williams, C., \& van Triest, S. (2009). The impact of corporate and national cultures on decentralization in multinational corporations. International Business Review, 18(2), 156-167. doi:https://doi.org/10.1016/j.ibusrev.2009.01.003 